\title{
Multivariate Analysis of Vehicular Emissions in Parts of Benin City, Edo State, Nigeria
}

\author{
*ILABOYA, IR; IYEKE, SD and ABULU, EI \\ Department of Civil Engineering, Faculty of Engineering, University of Benin, P.M.B 1154, Benin City, Edo State, Nigeria \\ *Corresponding Author Email: rudolph.ilaboya@uniben.edu
}

\begin{abstract}
The focus of this study is to monitor the incidence of vehicular emissions in some parts of Benin City in addition to studying the spatial variation of the pollutant using multivariate analysis of variance (MANOVA). Seven (7) georeferenced sampling points were employed for data collection and gaseous pollutants such as; dinitrogen oxide $\left(\mathrm{NO}_{2}\right)$, carbon monoxide $(\mathrm{CO})$ including the total radiation were monitored in the morning and evening for 35 days with the aid of portable toxic gas monitors and radiation alert meters. Also measured were maximum temperature and wind speed using infra-red thermometers and portable anemometer respectively. From the result, it was observed that for temperature, the mean \pm standard deviation during morning session was $30.549 \pm 1.3716$ and during evening season it was $28.879 \pm 1.1788$. For $\mathrm{NO}_{2}$, the mean \pm standard deviation during morning session was $0.0181 \pm 0.01119$ and during evening season it was $0.0230 \pm 0.01282$. For $\mathrm{CO}$, the mean \pm standard deviation during morning session was $0.5428 \pm$ 0.36396 and during evening season it was $0.6169 \pm 0.32395$. For total radiation, the mean \pm standard deviation during morning session was $0.247 \pm 0.1285$ and during evening season it was $0.281 \pm 0.1298$. On the significance difference of the overall results, it was revealed that the difference in concentration of vehicular emissions during the early hours of the morning and peak hours of evening is significant. With a calculated partial Eta squared based on Pillai's trace of 0.325 , it was concluded that; there exist about $32.50 \%$ variability among the dependent variables.
\end{abstract}

\section{DOI: https://dx.doi.org/10.4314/jasem.v25i4.26}

Copyright: Copyright (C) 2021 Iyeke et al. This is an open access article distributed under the Creative Commons Attribution License (CCL), which permits unrestricted use, distribution, and reproduction in any medium, provided the original work is properly cited.

Dates: Received: 14 February 2021; Revised: 26 March 2021; Accepted: 12 April 2021

Keywords: Air pollution, vehicular emissions, gaseous pollutants, multivariate analysis of variance

The lack of air quality data in most parts of Nigeria, results in low levels of awareness about air pollution and their resultant implications to human. It also limits people's capacity to predict the future challenges of air pollution thereby reducing their level preparedness towards future eventualities (Etim, 2016). African continent has the most notable lack of accessible air quality monitoring data, whilst facing numerous challenges related to air quality in the region (Abam and Unachukwu, 2009). It also has one of the urbanization rates of any region, with growing numbers of the population moving to large cities, where air pollution levels tend to be higher. In Nigeria, vehicular emissions are significantly on the rise due to the lack of poor transportation systems, giving way for unworthy road vehicles and unchecked use of private vehicles on the roads (Akpan and Ndoke, 1999). Many urban trips cover distances of less than $6 \mathrm{~km}$. Since the effectiveness of catalytic converters in the initial minutes of engine operation is small, the average emission per distance driven is very high in urban areas. Also, poorly maintained vehicles that lack exhaust after treatment systems are responsible for a major part of pollutant emissions (Han and Naeher,
2006). Traffic contributes to a range of gaseous air pollutants and to suspended particulate matter (PM) of different sizes and composition. Tail pipe emissions of primary particles from road transport account for up to $30 \%$ of PM2.5 in urban areas and other emissions related to road transport (such as those from resuspended road dust, and wear of tyres and brake linings) are the most important source of the coarse fraction of PM10 (Han and Naeher, 2006; Fu, 2001). According to the World Health Organization, Nigeria has a mortality rate for air pollution of 307.4 for every 100,000 people with an annual mean $\mathrm{PM}_{2.5}$ concentrations of $46.3 \mu \mathrm{g} / \mathrm{m}^{3}$ which is 4.5 times above the WHO guidelines for outdoor air quality. With the most polluted cities being Kano and Onitsha. Microscopic particles of $\mathrm{PM}_{2.5}$ micrometers or less in diameter can clog in human lungs and are linked to heart disease, stroke and lung cancer. The WHO recommends an annual mean exposure threshold of $10 \mu \mathrm{g} / \mathrm{m}^{3}$ to minimize the risk of health impacts from $\mathrm{PM}_{2.5}$. It is the general believe that real-time, public air quality information is essential not only to empower populations to respond to current conditions and protect human health, but also is a cornerstone in

*Corresponding Author Email: rudolph.ilaboya@uniben.edu 
generating public awareness and driving action to combat air pollution in the long-term (Koku and Osuntogun, 2007). The objective of this study is to evaluate the spatial variability of vehicular emissions in some parts of Benin City, Nigeria using multivariate analysis of variance

\section{MATERIALS AND METHODS}

Description of study area: The study area is limited to some parts of Benin City particularly Ugbowo and environs where serious traffic jam is experienced on daily bases. Benin City serves as the principal administrative and socio-economic center for both Oredo Local Government Area and Edo State in Nigeria. Benin City is a humid tropical urban settlement which comprises three Local Government Areas namely Egor, Ikpoba Okha and Oredo. It is located within latitudes $6^{0} 20^{\prime} \mathrm{N}$ and $6^{0} 58^{\prime} \mathrm{N}$ and longitudes $5^{0} 35^{\prime} \mathrm{E}$ and $5^{0} 41^{\prime} \mathrm{E}$. It broadly occupies an area of approximately $112.552 \mathrm{sq} \mathrm{km}$. This extensive coverage suggests spatial variability of weather and climatic elements. Benin City lies visibly in the southern most corner of a dissected margin: a prominent topographical unit which lies north of the Niger Delta, West of the lower Niger Valley, and South of the Western Plain (Okhakhu, 2010). The specific locations employed for data collection are presented in Figure 1

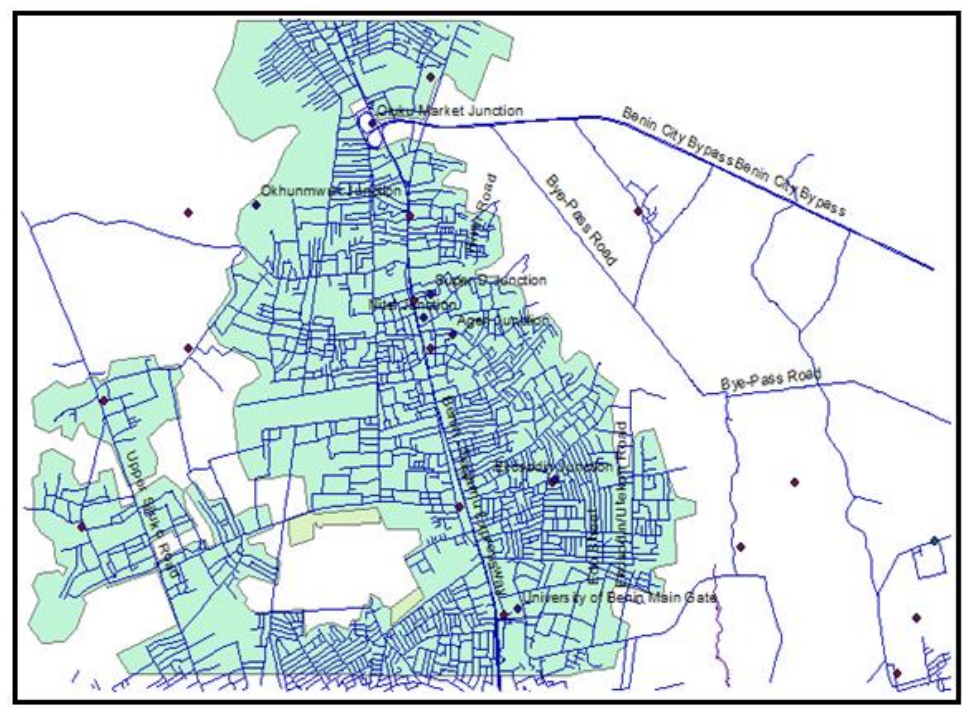

Fig 1: Map of study area

Data collection/Preliminary Analysis: Seven (7) georeferenced points, namely; University of Benin Main Gate, Ekosodin junction, Agen Junction, Super D junction, Nitel junction, Okhunmwun junction and Oluku Market junction were used for data collection. Dinitrogen oxide $\left(\mathrm{NO}_{2}\right)$, carbon monoxide $(\mathrm{CO})$ and total radiation were monitored in the morning and evening for 35 days with the aid of portable toxic gas monitors and radiation alert meters. Maximum temperature and wind speed were also measured using infra-red thermometers and portable anemometer. To ascertain the quality of the data, selected preliminary analysis using different statistical techniques, namely outlier detection using seasonal box plot method as proposed by Levi et al., (2009), test of homogeneity of data using the residual mass curve as proposed by Raes et al., (2006), test of normality using Jarque-Bera method and test of reliability using one-way analysis of variance were done.
Assessment of temporal variability: To study the variation in the concentration of vehicular emission occasioned by temporal variability (time of measurement), multivariate analysis of variance (MANOVA) was employed (Alkarkhi et al., 2008).

\section{RESULTS AND DISCUSSION}

To ascertain the normality of the data, Jarque-Bera test statistics was computed and presented in Figure 2 From the result of Figure 2, the calculated Jarque-Bera test value was observed to be 20.50813. Since the Jarque-Bera test value is greater than 10 with a (pvalue) that is less than the $5 \%$ significant value, the null hypothesis of normality was rejected and it was concluded that the measured $\mathrm{NO}_{2}$ records did not follow a normal distribution. This was expected owing to the influence of temperature and wind speed on the dynamic dispersion of gaseous air pollutants. The same approach was applied to other pollutants and the results showed a non-normally distributed trend. On whether the data employed for the analysis is devoid 
of outlier, the seasonal box plot presented in Figure 3 was employed.

The presence of outlier is normally indicated with a square box or circle containing a value inside it. This was not noticeable in Figure 3 hence; it was concluded that the measured $\mathrm{NO}_{2}$ data were devoid of possible outlier. The same approach was applied to other pollutants and the results showed that all the variables (air quality data) were devoid of outlier.

To ascertain the reliability of the data, two-way mixed model having a confidence interval of $95 \%$ (p-

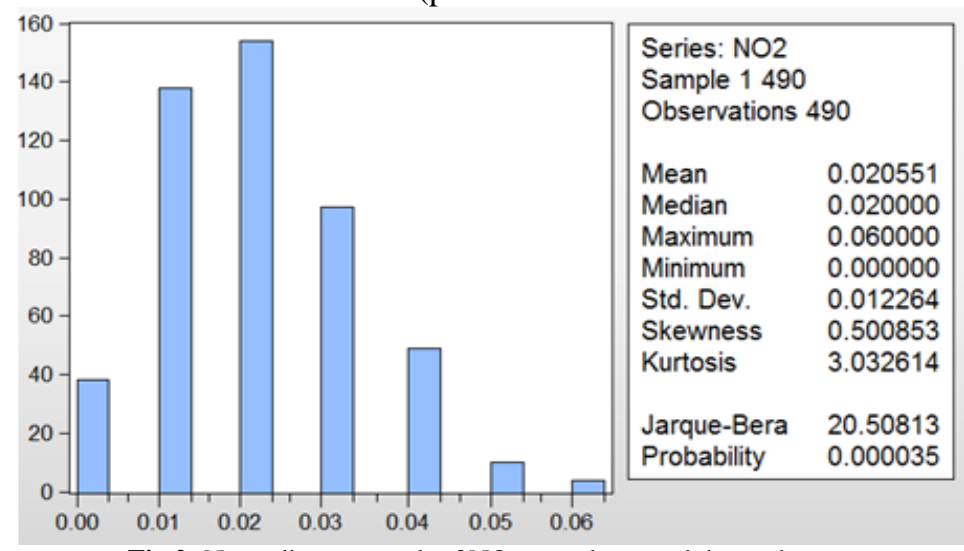

Fig 2: Normality test result of $\mathrm{NO}_{2}$ records around the study area

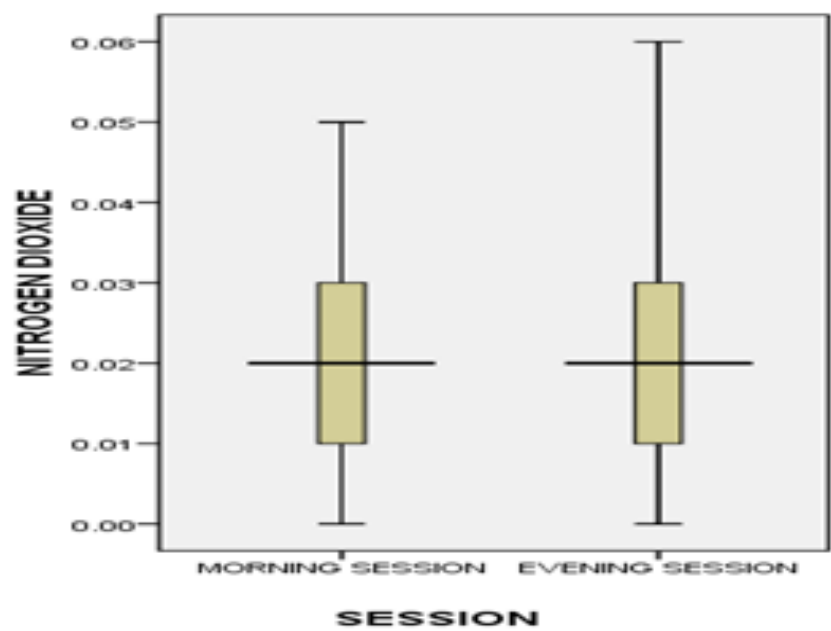

Fig 3: Seasonal box plot for assessing the presence of outliers in $\mathrm{NO}_{2}$ data

Table 1: Analysis of variance (ANOVA)

\begin{tabular}{llllll}
\multicolumn{5}{c}{ Table 1: Analysis of variance $($ ANOVA) } \\
\hline & Sum of Squares & df & Mean Square & F & Sig \\
\hline Between People & 282.353 & 489 & 0.577 & & \\
Within People Between items & 318289.685 & 3 & 106096.562 & $1.683 E 5$ & 0.00 \\
Residual & 924.584 & 1467 & 0.630 & & \\
Total & 319214.269 & 1470 & 217.153 & & \\
Total & 319496.622 & 1959 & 163.092 & & \\
\hline
\end{tabular}

At $0.05 \mathrm{df}$, with a computed p-value of 0.000 as observed in Table 1, the null hypothesis was accepted and it was concluded that the data are good and cam be employed for further analysis. value $=0.05)$ and initial test value of 0 was employed. The null hypothesis of reliability was formulated as follows;

H1: Data are not reliable

Using the Fisher's probability test (F-test), the analysis was conducted and the one-way analysis of variance (ANOVA) table was generated and presented in Table 1
To ascertain the presence of temporal variability occasioned by change in the time of measurement and also determine the degree of variability, multivariate analysis of variance was employed. The first step in the assessment of temporal variability is to compute 
the Mahalanobis constant and the descriptive statistics of all the dependent variables (air quality data). The maximum calculated value of Mahalanobis constant based on MANOVA was observed to be 15.86648 . With degree of freedom equals 4 (number of dependent variables) the critical value of Mahalanobis constant was (20.52). Since $15.86648<20.52$, it was concluded that the assumptions of multivariate outliers have not been violated hence the use of multivariate analysis of variance to study the presence of temporal variability was justified. The descriptive statistics is presented in Table 2

Table 2: Descriptive statistics of air quality data

\begin{tabular}{lccc}
\hline Session & Mean & Std. Deviation & $\mathbf{N}$ \\
\hline Temperature & & & \\
Morning Session & 30.549 & 1.3716 & 245 \\
Evening Session & 28.879 & 1.1788 & 245 \\
Total & 29.714 & 1.5268 & 490 \\
Nitrogen Dioxide & & & \\
Morning Session & 0.0181 & 0.01119 & 245 \\
Evening Session & 0.0230 & 0.01282 & 245 \\
Total & 0.0206 & 0.01226 & 490 \\
Carbon Monoxide & & & \\
Morning Session & 0.5428 & 0.36396 & 245 \\
Evening Session & 0.6169 & 0.32395 & 245 \\
Total & 0.5799 & 0.34618 & 490 \\
Total Radiation & & & \\
Morning Session & 0.247 & 0.1285 & 245 \\
Evening Session & 0.281 & 0.1298 & 245 \\
Total & 0.264 & 0.1302 & 490 \\
\hline
\end{tabular}

From the results of Table 2, it was observed that there is a significant difference between the calculated mean and standard deviation of all the dependent variables as a function of sampling time (morning and evening). For temperature, the mean \pm standard deviation during morning session was observed to be $30.549 \pm 1.3716$ and during evening season it was observed to be $28.879 \pm 1.1788$. For $\mathrm{NO}_{2}$, the mean \pm standard deviation during morning session was observed to be $0.0181 \pm 0.01119$ and during evening season it was observed to be $0.0230 \pm 0.01282$. For CO, the mean \pm standard deviation during morning session was observed to be $0.5428 \pm 0.36396$ and during evening season it was observed to be $0.6169 \pm 0.32395$. For total radiation, the mean \pm standard deviation during morning session was observed to be $0.247 \pm 0.1285$ and during evening season it was observed to be 0.281 \pm 0.1298 . The difference in the mean and standard deviation suggest the presence of imaginative variance which is temporal variation occasioned by change in sampling time (morning and evening). In multivariate analysis of variance, we set out to test the null hypothesis that observed covariance matrix of all the dependent variables (gaseous emission concentration) are equal across group (morning and evening) that is; there is no variation in the concentration of the measured parameters. If the calculated p-value is less than $0.05(\mathrm{p}<0.05)$ we reject the null hypothesis and conclude that the assumption of equal covariance matrices across group has not been satisfied; an indication that temporal variability exists among the group. The computed covariance matrix for the corrected model and season is presented in Table 3.

Table 3: Computed covariance matrix for corrected model

\begin{tabular}{|c|c|c|c|c|c|c|c|c|}
\hline Source & $\begin{array}{l}\text { Type II Sum } \\
\text { of Square }\end{array}$ & df & $\begin{array}{c}\text { Mean } \\
\text { Square }\end{array}$ & $\mathbf{F}$ & Sig. & $\begin{array}{c}\text { Partial Eta } \\
\text { Square }\end{array}$ & $\begin{array}{c}\text { Noncent } \\
\text { Parameter }\end{array}$ & $\begin{array}{c}\text { Observed } \\
\text { Power }\end{array}$ \\
\hline Corrected Model Temperature & 344.891 & 1 & 344.891 & 209.055 & .000 & .300 & 209.055 & 1.000 \\
\hline Nitrigen Dioxide & $.003^{\mathrm{c}}$ & 1 & .003 & 19.959 & .000 & .039 & 19.959 & .994 \\
\hline Carbon Monoxide & $.674^{\mathrm{d}}$ & 1 & .674 & 5.676 & .018 & .011 & 5.676 & .662 \\
\hline Total Radiation & $.144^{\mathrm{e}}$ & 1 & .144 & 8.629 & .003 & .017 & 8.629 & 834 \\
\hline Intercept Temperature & 432634.057 & 1 & 432634.057 & $2.645 \mathrm{E} 5$ & .000 & .998 & 264540.998 & 1.000 \\
\hline Nitrigen Dioxide & .207 & 1 & .207 & $1.429 \mathrm{E} 3$ & .000 & .745 & 1429.228 & 1.000 \\
\hline Carbon Monoxide & 164.755 & 1 & 164.755 & $1.388 \mathrm{E} 3$ & .000 & .740 & 1387.909 & 1.000 \\
\hline Total Radiation & 34.172 & 1 & 34.172 & $2.048 \mathrm{E} 3$ & .000 & .808 & 2047.685 & 1.000 \\
\hline Session Temperature & 341.891 & 1 & 341.891 & 209.055 & .000 & .300 & 209.055 & 1.000 \\
\hline Nitrigen Dioxide & .003 & 1 & .003 & 19.959 & .000 & .039 & 19.959 & .994 \\
\hline Carbon Monoxide & .674 & 1 & .674 & 5.676 & .018 & .011 & 5.676 & .662 \\
\hline Total Radiation & .144 & 1 & .144 & 8.629 & .003 & .017 & 8.629 & .834 \\
\hline Error Temperature & 798.082 & 488 & 1.635 & & & & & \\
\hline Nitrigen Dioxide & .071 & 488 & .000 & & & & & \\
\hline Carbon Monoxide & 57.929 & 488 & .119 & & & & & \\
\hline Total Radiation & 8.144 & 488 & .017 & & & & & \\
\hline Total Temperature & 433774.030 & 490 & & & & & & \\
\hline Nitrigen Dioxide & .281 & 490 & & & & & & \\
\hline Carbon Monoxide & 223.358 & 490 & & & & & & \\
\hline Total Radiation & 42.460 & 490 & & & & & & \\
\hline Corrected Total Temperature & 1139.973 & 489 & & & & & & \\
\hline Nitrigen Dioxide & .074 & 489 & & & & & & \\
\hline Carbon Monoxide & 58.603 & 489 & & & & & & \\
\hline Total Radiation & 8.288 & 489 & & & & & & \\
\hline
\end{tabular}


From the results of Tables 3, it was observed that the computed significant values ( $p$-value) for both the corrected model and season were less than 0.05; ( $\mathrm{p}<$ 0.05 ), hence the null hypothesis was rejected and it was concluded that the covariance matrix assumption was not satisfied. This means that the covariance matrices of the dependent variables are not equal across group an indication that temporal variability exists. It was concluded based on the covariance matrix that the variation in the dependent variables is due to variation in time of sampling.
Different statistical method for computing the F-value for multivariate analysis of variance exits in literature. One of them is the Roy's largest root which is probably the most acceptable and also the most susceptible to deviation in the covariance matrix. The next is the Pillai's Trace followed by Wilk's Lambda. Pillai's Trace is the least sensitive to the violation of the assumption of covariance matrix hence it was selected for this study. Result of multivariate test statistics computed to study the effect of temporal variability is presented in Table 4 .

\begin{tabular}{|c|c|c|c|c|c|c|c|c|}
\hline Effect: & Value & $\mathbf{F}$ & $\begin{array}{l}\text { Hypothesis } \\
\text { df }\end{array}$ & $\begin{array}{l}\text { Error } \\
\text { df }\end{array}$ & Sig. & $\begin{array}{l}\text { Partial } \\
\text { Eta } \\
\text { Square }\end{array}$ & $\begin{array}{l}\text { Noncent } \\
\text { Parameter }\end{array}$ & $\begin{array}{l}\text { Observed } \\
\text { Power }\end{array}$ \\
\hline \multicolumn{9}{|l|}{ Intercept } \\
\hline Pillai's Trace & .998 & $6.922 \mathrm{E} 4^{\mathrm{a}}$ & 4.000 & 485.00 & .000 & .998 & 276887.663 & 1.000 \\
\hline Wilks' Lambda & .002 & $6.922 \mathrm{E} 4^{\mathrm{a}}$ & 4.000 & 485.00 & .000 & .998 & 276887.663 & 1.000 \\
\hline Hotellimg's Trace & 570.902 & $6.922 \mathrm{E} 4^{\mathrm{a}}$ & 4.000 & 485.00 & .000 & .998 & 276887.663 & 1.000 \\
\hline $\begin{array}{l}\text { Roy's Largest Root } \\
\text { Session: }\end{array}$ & 570.902 & $6.922 \mathrm{E} 4^{\mathrm{a}}$ & 4.000 & 485.00 & .000 & .998 & 276887.663 & 1.000 \\
\hline Pillai's Trace & .325 & $58.497^{\mathrm{a}}$ & 4.000 & 485.00 & .000 & .325 & 233.986 & 1.000 \\
\hline Wilks' Lambda & .675 & $58.497^{\mathrm{a}}$ & 4.000 & 485.00 & .000 & .325 & 233.986 & 1.000 \\
\hline Hotellimg's Trace & .482 & $58.497^{\mathrm{a}}$ & 4.000 & 485.00 & .000 & .325 & 233.986 & 1.000 \\
\hline Roy's Largest Root & .482 & $58.497^{\mathrm{a}}$ & 4.000 & 485.00 & .000 & .325 & 233.986 & 1.000 \\
\hline
\end{tabular}

From the result of Table 4, it was observed that the computed significant value ( $\mathrm{p}$-value) based on Roy's largest root, Wilk's Lambda, Hotelling's Trace and the Pillai's Trace were less than $0.05(\mathrm{p}=0.00)$ hence, the null hypothesis that the air quality parameters are the same for the two groups (morning and evening) was rejected and it was concluded that temporal variability actually exist. To calculate the percentage variability that is accounted for due to temporal variation, the partial Eta squared value of the Pillai's trace was employed. From the result of Table 4, the calculated partial Eta squared of the Pillai's trace was observed to be 0.325 which indicates $32.50 \%$ variability among the dependent variables occasioned by change in the period of measurement. In addition, when the null hypothesis of equal variance assumption is rejected, then the observed power function based on Pillai's trace must be between 0.9-1.00. Again from the result of Table 4, it was observed that the calculated power function based on Pillai's trace is 1.00 for both intercept and session. This validates the initial claim that temporal variability exists between the dependent variables.

Conclusion: Since the critical value of Mahalanobis constant was less than the calculated value, it was concluded that the assumptions of multivariate outliers have not been violated hence the use of multivariate analysis of variance to study the presence of temporal variability. In addition, with a calculated partial Eta squared based on Pillai's trace of 0.325 , it was concluded that; there exist about $32.50 \%$ variability among the dependent variables occasioned by change in the period of measurement. It is important to note that temperature and wind spend are important variables that can affect the dispersion of pollutants

\section{REFERENCES}

Abam, FI and Unachukwu, GO (2009). Vehicular Emissions and Air Quality standards in Nigeria. European J. Sci. Res. 34 (4), 550-560

Akpan, UG and Ndoke, PN (1999). Contribution of vehicular traffic emission to $\mathrm{CO} 2$ emission in Kaduna and Abuja; Federal University of Technology, Minna Nigeria

Alkarkhi, AFM; Ahmad, A; Ismail, N; Easa, A and Omar, K (2008). Assessment of surface water through Multivariate Analysis. J. Sustain. Develop. 1(3), 27-33

Etim, EU (2016). Air pollution emission inventory along a major traffic route within Ibadan metropolis, southwestern Nigeria. Afr. J. Environ. Sci. Technol. 10 (11), 432-438

$\mathrm{Fu}, \mathrm{L}$ (2001). Assessment of vehicle pollution in China. Journal of the air and waste management, $51(5), 658-68$ 
Han, X and Naeher, LP (2006). A review of trafficrelated air pollution exposure assessment studies in the developing world. Environ. Inter. 32, $106-$ 120

Koku, CA and Osuntogun, BA (2007). EnvironmentalImpacts of Road Transportation in Southwestern States of Nigeria. J. Appl. Sci. 7 (16), 2536-2360

Levi, DB; Julie, EK; Olsen, JR; Pulwarty, RS; Raff, DA; Turnipseed, DP; Webb, RS and Kathleen, DW (2009). Climate Change and Water Resources Management. A Federal Perspective. $1331,1-72$
Okhakhu, PA (2010): Environmental and Human Challenges in the Niger-Delta Region of Nigeria. J. Environ. Earth. Sci. 4(23), $112-134$

Raes, D; Willens, P and Gbaguidi, S (2006), Rainbow - A software package for analyzing data and testing the homogeneity of historical data sets, 1 , 1-15

Shrestha, S and Kazama, F (2007). Assessment of surface water quality using multivariate statistical techniques: A case study of the Fuji river basin, Japan. Environ. Modelling. Software. 22(4), 464475 